вредоносных компонентов. Вирусная база данных автоматически обновляется и пополняется. Именно из нее берется информация для сличения подозрительных объектов. Сканер и фильтр проверяют файлы на съемных носителях и во время типовых операций на компьютере.

\title{
Криптографическая защита
}

Под криптографией подразумевают способы преобразования информации для защиты от нежелательного использования либо воздействия.

Преобразованием производится с помощью специальных алгоритмов шифрования. Шифрование может проводиться симметрично - создание только одного ключа, который шифрует и дешифрует данные, либо ассиметрично - создание двух ключей, один шифрует и является общедоступным, другой - дешифрует и является секретным.

Одним из способов шифрования является создание электронной цифровой подписи на основе ассиметричного алгоритма шифрования. Этот реквизит дает возможность проверить документ на наличие искажений с момента создания ключа, а также подтвердить принадлежность подписи владельцу сертификата этого ключа. Это специальный файл, который содержит в сжатом виде информацию о документе в виде зашифрованного образа.

Контроль целостности документов позволяет обнаружить подделку, в том числе при случайном воздействии на документ. Такая защита от изменений делает подделывание нерентабельным.

\section{$* * *$}

1. Грибунин, В. Г., Чудовский В.В., Комплексная система защиты информации на предприятии : учебное пособие / В. Г. Грибунин, В.В. Чудовский. Москва : Издательский центр «Академия», 2009 г. -416 c.

2. Блинов, А. М., Информационная безопасность : учеб. пособие. Часть 1 / А. М. Блинов. СПБГУЭФ, 2010 г. -96 c.

3. Гатчин, Ю. А., Теория информационной безопасности и методология защиты информации : учеб. пособие / Ю. А. Гатчин, В. В. Сухостат. СПбГУ ИТМО, 2010 г. -98 с.

Тимофеева Н.В., Костылев Н.С.

\section{Проектирование системы информационной поддержки деятельности автошколы}

Северный (Арктический) федеральный университет имени М.В. Ломоносова doi: $10.18411 / \mathrm{j}-05-2021-21$

(Россия, Северодвинск)

\section{Аннотация}

Статья посвящена вопросу оптимизации деятельности автошколы с помощью внедрения системы информационной поддержки. В данной работе приведен вариант проектного решения проблем, возникающих в ходе поддержки учебного процесса.

Ключевые слова: автошкола, личное дело обучающегося, договор, теория, практика вождения, система информационной поддержки.

\section{Abstract}

The article is devoted to the issue of optimizing the activities of a driving school through the introduction of an information support system. In this paper, a variant of the design solution of problems arising in the course of supporting the educational process is given.

Keywords: driving school, student's personal file, contract, theory, driving practice, information support system. 
Услуги автошкол давно стали востребованы в повседневной жизни, и данная востребованность неуклонно растет. Автомобиль уже давно превратился из роскоши в незаменимое средство передвижения. Граждане, желающие получить право на управление автотранспортом, обязаны, по Российскому Законодательству, пройти курс обучения, сдать экзамены для получения допуска к управлению транспортными средствами [1].

Автошкола, в свою очередь, обязана получить лицензию на образовательную деятельность, с указанием конкретных категорий управления транспортом.

Автошкола, деятельность которой рассматривается в данной работе имеет свой автопарк, штат сотрудников: преподавателей теории; инструкторов практических навыков со стажем не менее 3-х лет; механиков для обеспечения полной исправности учебных автомобилей; администратора. Во главе организации стоит директор. Автошкола арендует помещение для проведения теоретических занятий, а также площадку для отрабатывания упражнений по вождению.

Работа автошколы должна быть оперативной: проведение консультаций с будущими учениками, заключение договора и расчет стоимости обучения, согласование расписания теоретических и практических занятий, подготовка и проведение внутренних экзаменов, реагирование на вопросы и претензии учеников и т.д. Один из способов оптимизировать работу - это внедрение современных технологий, в нашем случае, системы информационной поддержки деятельности, позволяющую оперативно вести документооборот автошколы. Первоначальным этапом разработки системы является анализ протекающих в организации процессов и всей документации.

Первым этапом администратор автошколы организовывает собрание по набору новой группы. Для этого на различных информационных ресурсах (СМИ, радио, газеты, группы города в социальных сетях) публикуется рекламное объявление, в котором указаны адрес автошколы, дата и время проведения организационного собрания.

На организационном собрании обговариваются все условия по предоставлению образовательных услуг и при достижении согласия сторон, составляется договор с каждым участником собрания. Напечатанные формы договоров выдаются каждому присутствующему. Будущий обучаемый вписывает свои личные, контактные и другие необходимые данные. Договор подписывается каждой стороной. Со стороны автошколы договор подписывает директор, который присутствует на собрании.

После подписания договора, будущий ученик оплачивает обучение частично или полностью, согласно условиям договора, и предоставляет документ об оплате администратору (чек, платежный документ).

К договору ученик прилагает следующие документы:

- копию паспорта (2 и 3 лист - с фотографией и пропиской). Для подтверждения копии ученик предоставляет оригинал паспорта;

- одна фотография $3 \times 4$, цветная, с правым уголком;

- медицинская справка водительская и её копия с двух сторон.

На основании подписанных договоров и произведенной оплаты администратор формирует группу. Группа составляется под программу обучения, согласно указанной в договоре категории транспортного средства. Каждой группе назначается преподаватель теории и несколько инструкторов. На теоретические занятия администратором составляется расписание для всей группы.

Для обучения вождению каждому ученику назначается инструктор. Администратор проверяет занятость каждого инструктора, и зависимости от его загруженности, распределяет учеников. Расписание вождений согласовывается каждым 
учеником и инструктором индивидуально. Данные расписания доводятся до сведения администратора. Данные расписаний администратор сводит в журнал группы.

Ученик посещает теоретические и занятия по управлению транспортного средства.

После каждого проведенного занятия преподаватель теории отмечает в журнале группы, а инструктор - в карточке индивидуального вождения: тему, посещаемость и результат проведения занятия, его длительность. Эти сведения также передаются администратору с разной степенью периодичности.

Администратор контролирует количество проведенных теоретических и практических занятий, как со стороны сотрудников, так и со стороны обучающихся. На основании таких данных администратор составляет отчеты по учету рабочего времени сотрудников и отчеты по обучению учеников автошколы.

После прохождения полного курса ученики сдают внутренний экзамен, включающий теорию и практику в присутствии старшего инструктора. По итогам экзамена оформляется экзаменационная ведомость.

После сдачи внутренних экзаменов группе предоставляется дата для сдачи экзамена в ГИБДД. Если ученик не готов, он может принять решение сдавать экзамен в другую дату.

Если ученики готовы, то автошкола выполняет свои договорные обязательства и инструктора сопровождают группу на экзамен в ГИБДД, передавая все необходимые документы (свидетельство об окончании автошколы государственного образца, водительская карточка, медицинская ф3справка и т.д.), а также предоставляет учебный автомобиль [2].

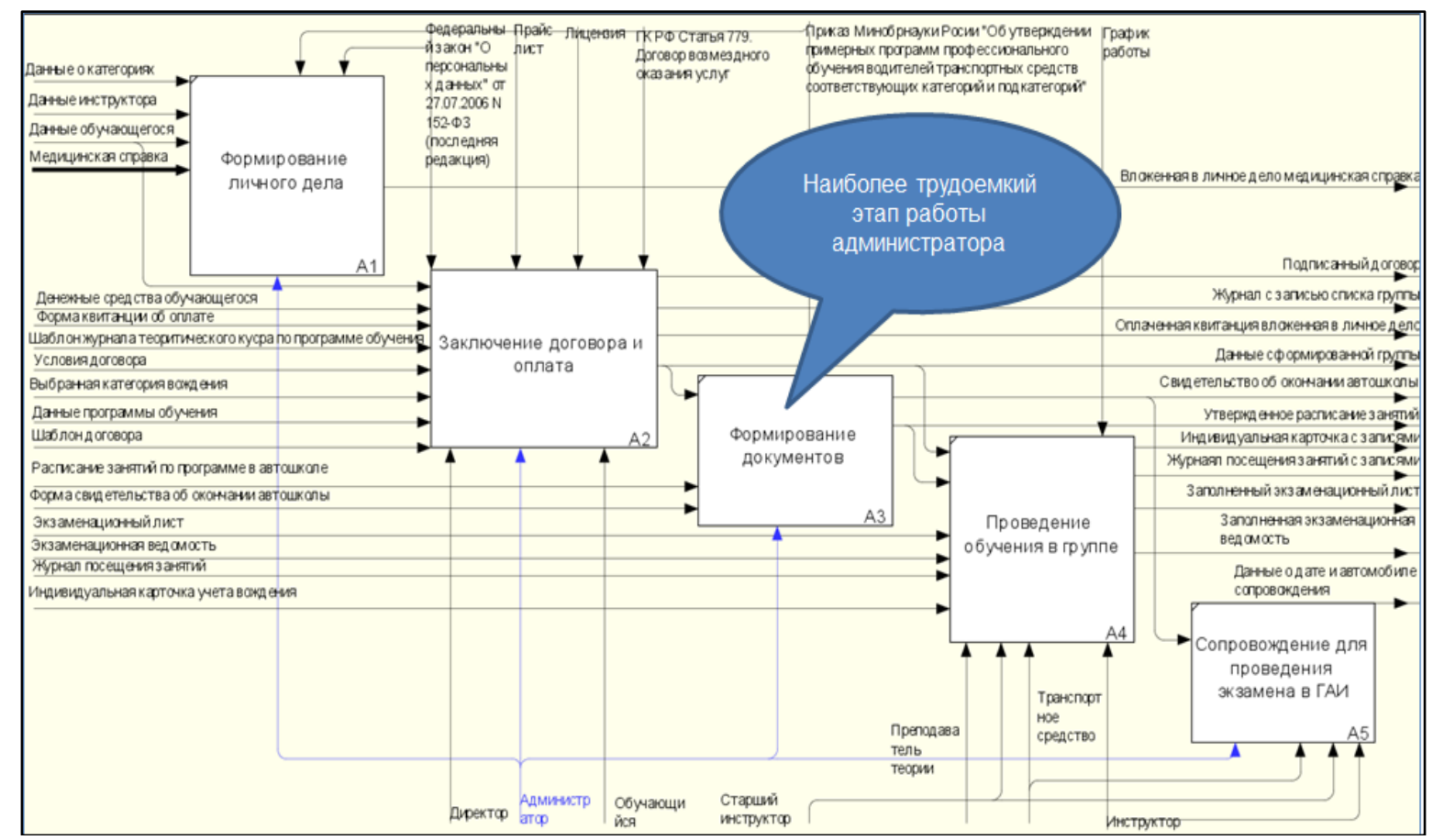

Рисунок 1 - Декомпозищия диаграммы АО «Деятельность автошкольл»

На основании проанализированных бизнес-процессов при работе с документами автошколы была построена диаграмма в нотации IDEF0, представленная на рисунке 1 и полная функциональная структура системы информационной поддержки, представленная на рисунке 2. Разработка диаграмм является вторым этапом проектирования. Логическая модель предметной области, лежащей в основе разработанной системы приведена на рисунке 3. 


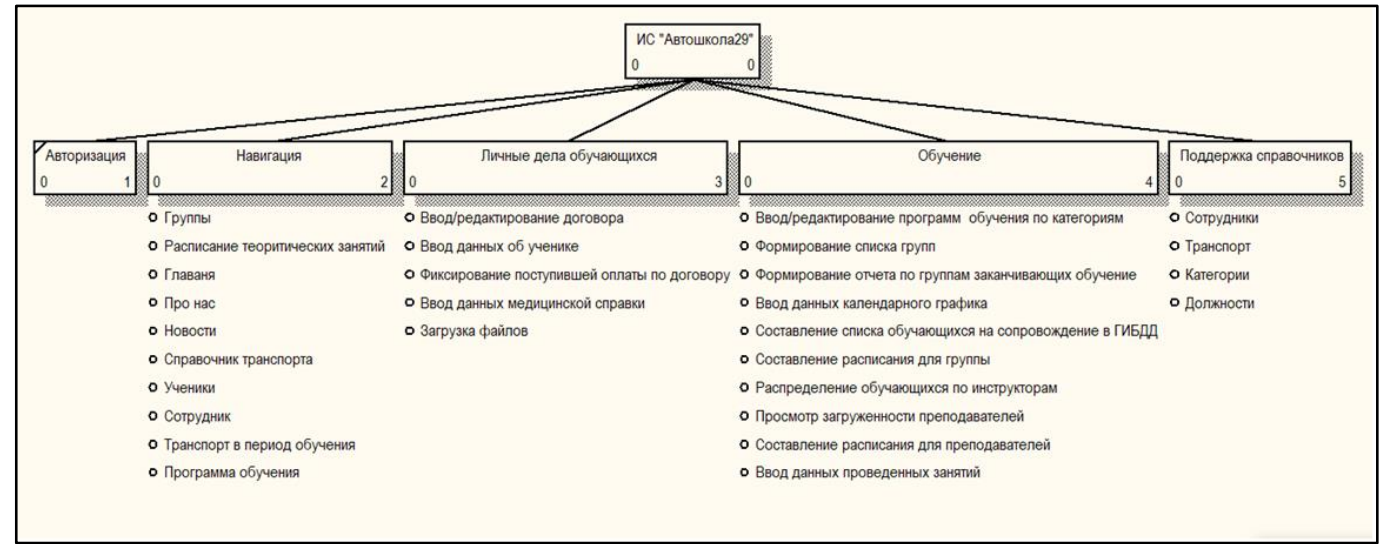

Рисунок 2 - Функциональная структура

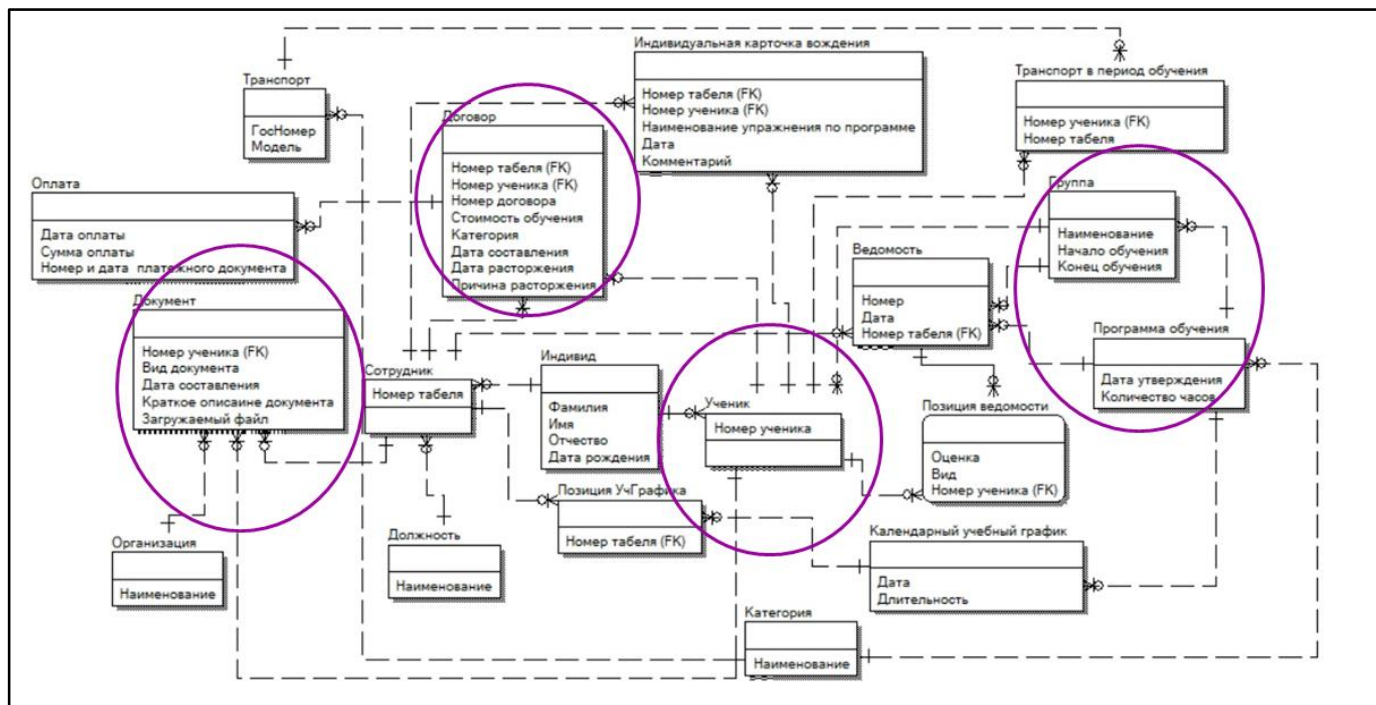

Рисунок 3 - Логическая модель данных

Следующий этап - это создание системы, хранящей в себе всю информацию о протекании учебного процесса в автошколе. В системе предусмотрена авторизация, чтобы разделить функционал для определенного типа сотрудника. Основной задачей системы является формирование различного рода документации, позволяющих сопровождать и оценивать учебный процесс в любой момент времени.

Система разработана с использованием средств СУБД SQLite и интегрированной среды разработки JetBrains PyCharm. На рисунках 4 - 7 представлены прототипы экранных форм, протестированных на рабочем месте администратора.

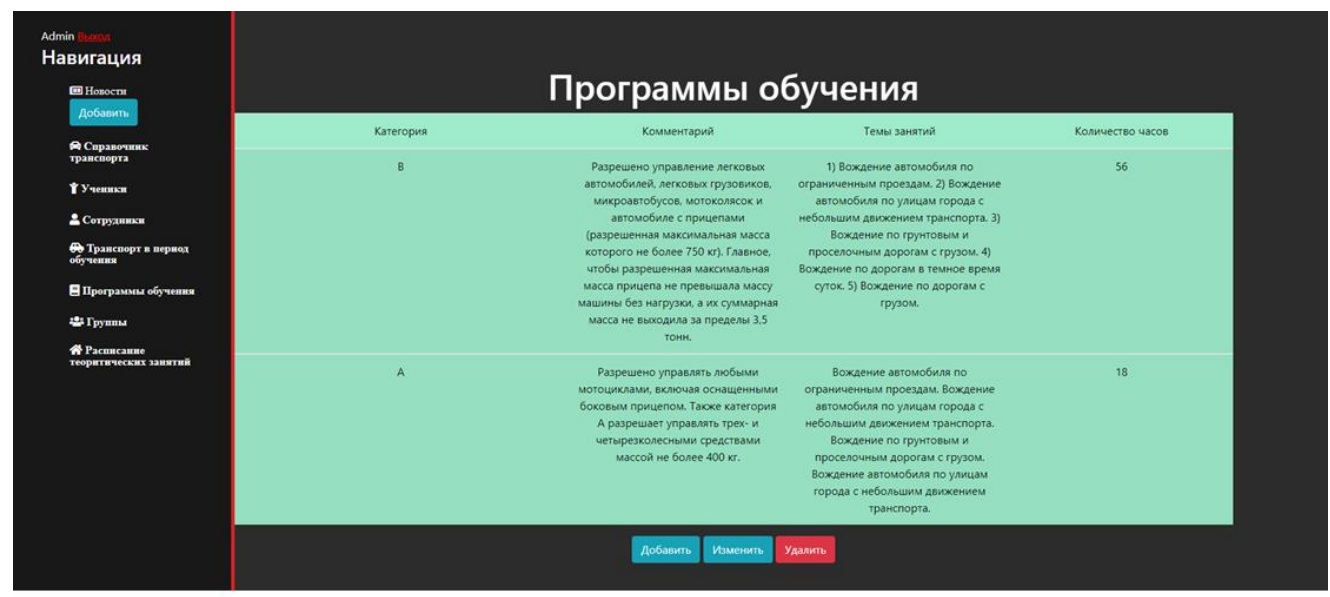

Рисунок 4 - Прототип экранной формы Программы обучения 


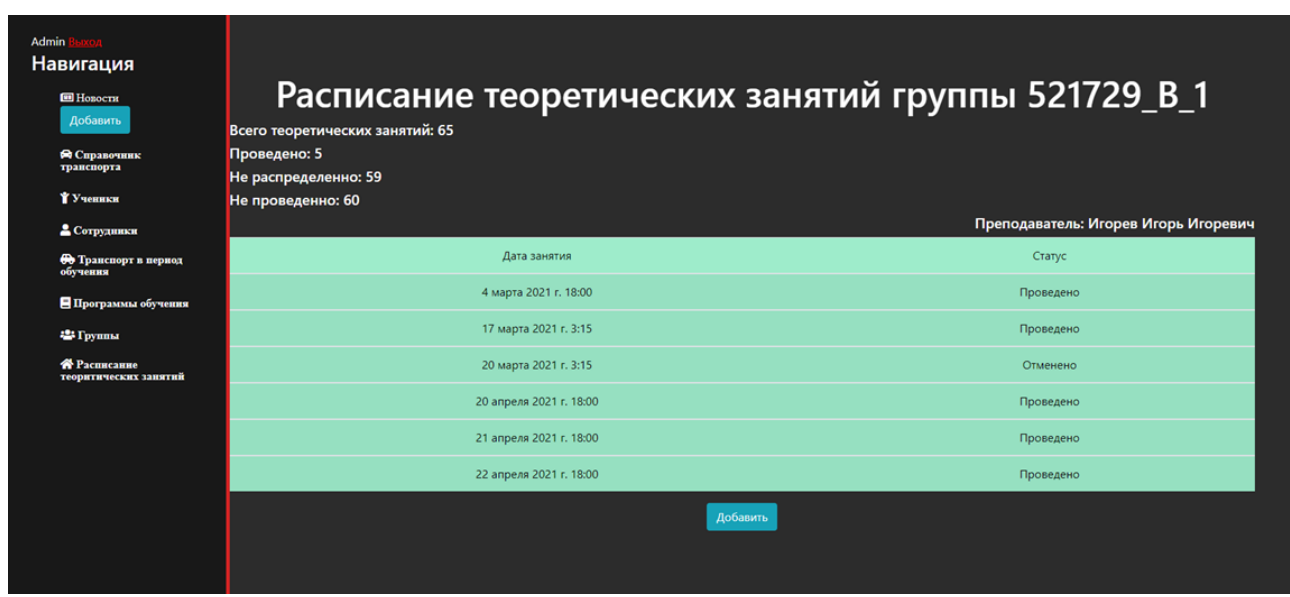

.Рисунок 5 - Печатная форма Расписание теоретических занятий

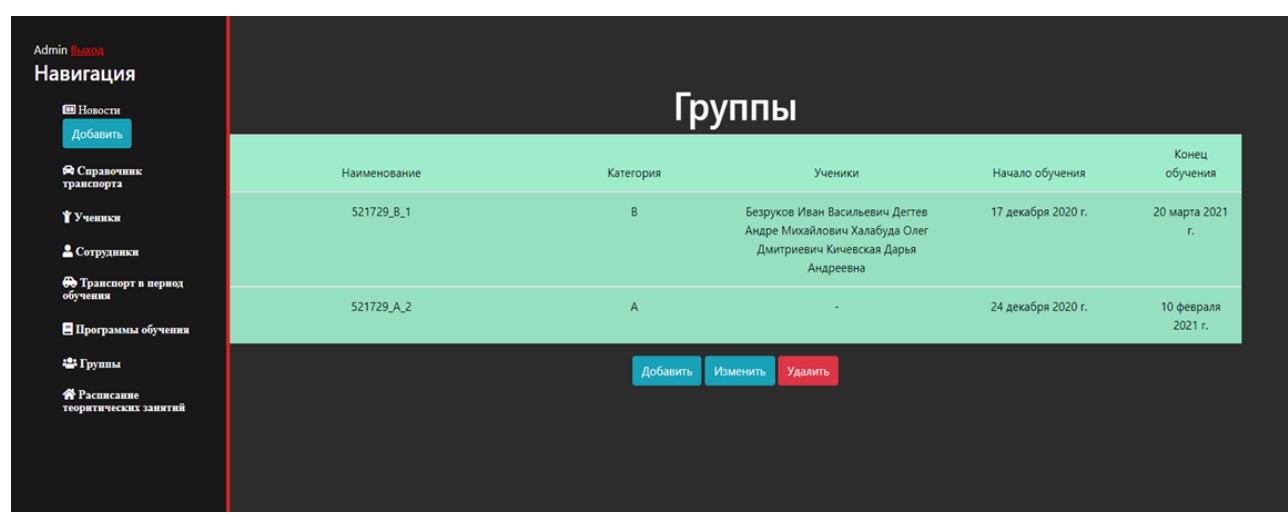

Рисунок 6-Прототип экранной формы Группь

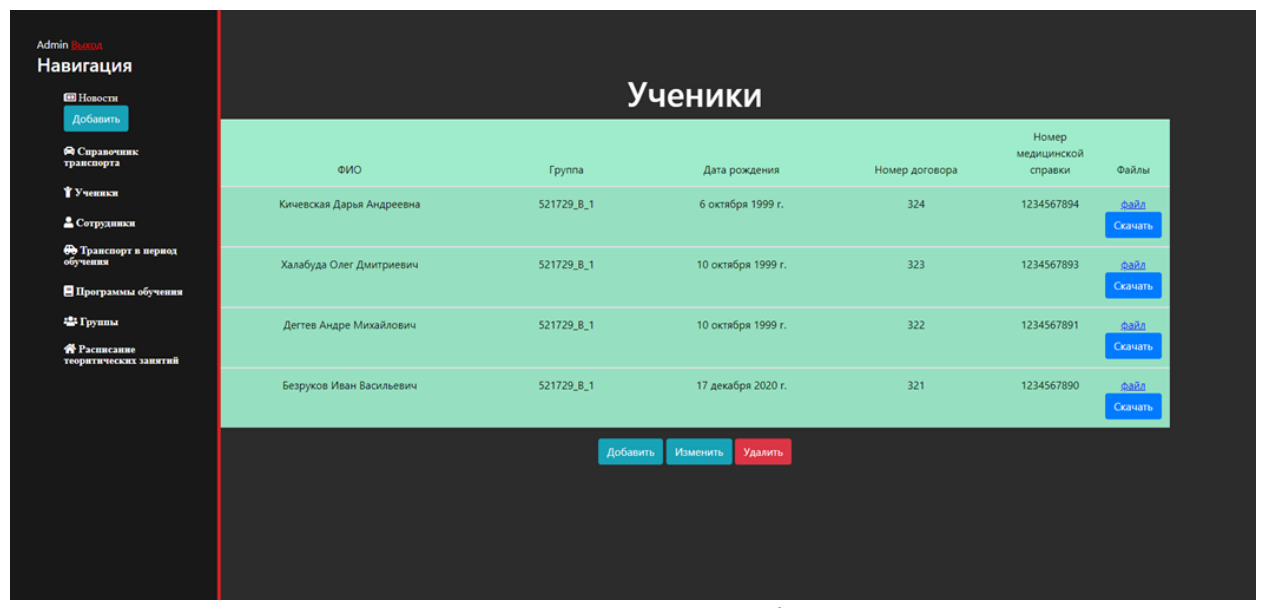

Рисунок 7 - Прототип экранной формы Ученики

После проведения начального этапа рабочего тестирования системы можно сделать вывод, что внедрение системы позволит сократить время на сбор и обработку данных о ходе учебного процесса, планировать загруженность сотрудников, а также при росте количества групп и желающих обучиться руководитель автошколы получает возможность понимать, каким образом планировать дальнейшее развитие организации. Таким образом, существует необходимость в доработке, полном тестировании и внедрении системы в деятельность автошколы.

$$
* * *
$$

1. СПС Консультант Плюс / Приказ Минобрнауки России от 26.12.2013 № 1408 (ред. от 19.10.2017) «Об утверждении примерных программ профессионального обучения водителей транспортных 
средств соответствующих категорий и подкатегорий» [Электронный ресурс]. Режим доступа: http://www.consultant.ru/document/cons_doc_LAW_165639/(дата обращения: 25.03.2021).

2. СПС Консультант Плюс / Постановление Правительства РФ от 24.10.2014 № 1097 (ред. от 20.12.2019) «О допуске к управлению транспортными средствами» (вместе с «Правилами проведения экзаменов на право управления транспортными средствами и выдачи водительских

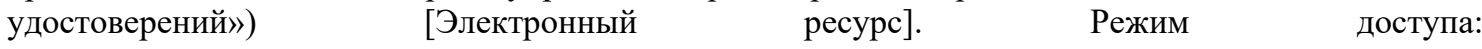
http://www.consultant.ru/document/cons_doc_LAW_170282/(дата обращения: 20.03.2021).

\section{Хаитбаева Д.3. \\ Развитие открытого программного обеспечения в сфере Web}

Национальный исследовательский университет ИТМО

(Россия, Санкт-Петербург)

doi: $10.18411 / \mathrm{j}-05-2021-22$

\section{Аннотация}

Статья включает в себя анализ понятий, значимых определений и терминологии в области использования открытого программного обеспечения. В роли одного из видов соавторства, а также способа создания сложного объекта, не связанного с предметом регулирования института интеллектуальной собственности, изучается позиционирование модели открытого ПО. Подведены итоги того, что современное российское правовое законодательное регулирования позволяет разрешить многие вопросы, возникающие при регулировании открытой модели творческого взаимодействия. Приведено обоснование факта, что участники исследуемой модели сотрудничества вправе лично выбирать правовой режим объектов, создаваемых ими.

Ключевые слова: открытая лицензия, открытая модель программного обеспечения, программное обеспечение с открытыми исходными данными в webсфере, соавторство; сложный объект.

\section{Abstract}

The article includes an analysis of concepts, significant definitions and terminology in the field of open source software use. As one of the types of co-authorship, as well as a way to create a complex object that is not related to the subject of regulation of the institute of intellectual property, the positioning of the open source software model is studied. The article summarizes the fact that the modern Russian legal and legislative regulation allows us to resolve many issues that arise when regulating the open model of creative interaction. The substantiation of the fact that the participants of the studied model of cooperation have the right to personally choose the legal regime of the objects created by them is given.

Key words: open license, open software model, open source software in the web, coauthorship; complex object.

Усиление процессов глобализации и информатизации, отражающееся на способах получения нового знания, моделях создания результатов интеллектуальной деятельности составляет основу нынешнего этап общественного развития. Технологическое распространение, позволяющее обеспечивать взаимодействие между лицами, вне зависимости от места их нахождения, а также гарантировать актуализацию междисциплинарных исследований, для проведения которых необходимо участие нескольких специалистов в различных областях выступают в качестве факторов, способствующих наращиванию тенденции создания результатов интеллектуальной деятельности именно совместным, а не единоличным трудом.

Тем не менее, несовершенству правового регулирования сферы интеллектуальной собственности применительно к отношениям по совместному созданию результатов интеллектуального труда посвящено достаточное количество зарубежных исследований. Это, в свою очередь, предотвращает улучшение результата 